\title{
New Pore Pressure Evaluation Techniques for LAGIA-8 Well, Sinai, Egypt as a Case Study
}

\author{
Ahmed Zakaria Noah \\ Exploration Department, Egyptian Petroleum Research Institute, Cairo, Egypt \\ Email: alaanooh@hotmail.com
}

Received 15 September 2015; accepted 25 January 2016; published 28 January 2016

Copyright (C) 2016 by author and Scientific Research Publishing Inc.

This work is licensed under the Creative Commons Attribution International License (CC BY). http://creativecommons.org/licenses/by/4.0/

(c) (i) Open Access

\begin{abstract}
Drilling into a geopressured zone will generally cause a change in a number of basic formation/ drilling relationships. This change is usually seen as a reversal of a gradual depth related trend in a lithologically uniform formation. Of all the geophysical methods, the reflection seismic method is essentially the only technique used to predict pore pressures. The seismic method detects changes of interval velocity with depth from velocity analysis of the seismic data. These changes are in turn related to lithology, pore fluid type, rock fracturing and pressure changes within a stratigraphic column. When the factors affecting the velocity are understood for a given area, a successful pressure prediction can be made. For clastic environments such as the Tertiary section of the Gulf of Mexico or the Niger delta, the interval velocity of the rocks increases with depth because of compaction. In these areas, deviations from normal compaction trends are related to abnormally high pore pressures. The adapted methods provide a much easier way to handle normal compaction trend lines. In addition to well log methods, pressure detection can be obtained via drilling parameters by applying Eaton's DXC methods. Seismic velocities have long been used to estimate pore pressure, indeed both these quantities are influenced by variations in rock properties such as porosity, density, effective stress and so on, and high pore pressure zones are often associated with low seismic velocities. Pressure prediction from seismic data is based on fundamentals of rock physics and seismic attribute analysis. This paper hence tries to assess the use of seismic waves as a viable means to calculate pore pressure, especially in areas where no prior drilling history can be found. Then we applied these methods on LAGIA-8 well, Sinai, Egypt as a case study. Pore pressure prediction from Seismic is a very essential tool to predict pore pressure before drilling operation. This could prevent the well problem as well blowout and to prevent formation damage, especially in areas where no prior drilling history can be found.
\end{abstract}

\section{Keywords}

Pore Pressure, Resistivity and Sonic Methods, Seismic Velocities, Formation Damage 


\section{Introduction}

The pressure can be calculated indirectly from petrophysical measurements. Petrophysical data can be acquired while drilling or after drilling a section. In the former case of the petrophysical sensors are placed behind the drill bit in operations known as Logging While Drilling (LWD) or Measurement While Drilling (MWD). The pore pressures in the reservoir rocks with high permeability are measured directly using a wireline tool with a pressure gauge, while the low permeability rocks (such as mud-rock), the porosity calculated from logs and computed or established a normal compaction tend of expected porosity for normal pressure. The final step is to find a relationship quantifies the pore pressure magnitude associated with a mismatch between the estimated mud-rock porosity from log response and the normal compaction trend.

\section{Pore Pressure Evaluation}

\subsection{Pore Pressure Prediction from Seismic}

Determining pore pressure from seismic interval velocities is no different than using the sonic log. The important difference is that the interval velocities that are calculated from the RMS velocities coming from stacking velocities are horizontal velocities while the sonic $\log$ is measuring the vertical velocity assuming the well is vertical. Determining pore pressure from seismic interval velocities is no different than using the sonic log. The important difference is that the interval velocities that are calculated from the RMS velocities coming from stacking velocities are horizontal velocities while the sonic log is measuring the vertical velocity assuming the well is vertical.

The velocity of sound (compressional, seismic, or P) waves propagating through a piece of rock is called the rock velocity. The rock velocity depends on many parameters: porosity, fluid saturation, state of stress, pore and confining stress, pore structure, temperature, pore fluid type and its thermodynamic state, lithology, clay content, cementation, and frequency of the propagating waves. Furthermore, these parameters are not independent of each other. Rock velocities in over-pressured zones are lower than those found at hydrostatic pressures. Low velocities in highly pressured zones are often related to thick shale sequences that have low sand layer occurrence (less than $10 \%$ of total thickness).

\section{Relationship of Rock Velocity and Porosity}

The literature is full of relationships between porosity (or bulk density) and velocity of a given rock type [1]. However, very little is published about such relationships for shales, where geo-pressuring occurs. For sonic logs,

1) Pickett-type equation [2] is frequently used:

$$
d t=A_{0}+B_{0} \varphi
$$

where: $d t$ is the sonic interval transit time (slowness) (usually expressed in microseconds per foot), and are lithology-dependent constants. $A_{0}$ and $B_{0}$ are lithology-dependent constants.

2) Gardner equation [3]. This is usually expressed as

$$
\rho_{b}-C^{\prime} V^{d^{\prime}}
$$

where: $V$ is interval velocity, and $c^{\prime}$ and $d^{\prime}$ are lithology-dependent constants.

3) Wyllie time-average equation [4]: relating porosity to transit time, namely,

$$
d t=\varphi d t_{f}+\left(d t_{m}\right)
$$

where: $d t_{f}$ and $d t_{m}$ are the transit times through the fluid and solid phases, respectively, is a special case of the Pickett-type equation.

4) Issler's (1992) equation [5]; published a very useful porosity-sonic transit-time equation for shales and mudstones based on logs and core measurements. It is an extension of a similar relationship published earlier by Raiga-Clemenceau et al. (1988).

$$
d t=d t_{m}(1-\varphi)^{-X}
$$

where: $d t_{m}$ is the travel time for the matrix, $d t$ is the log-derived traveltime, and $X$ is an acoustic formation factor 
dependent on lithology.

This is very similar to Archie's resistivity equation. The resistivity of fluid-filled porous rocks, $R$, is expressed in terms of $\varphi$, resistivity of water, $R_{w}$, and formation factor, $F$ :

$$
R=F R_{w}=a \varphi^{-m} R_{w}
$$

Here, $a$ and $m$ are lithology dependent constants [7].

All seismic methods for pressure prediction use either explicitly or implicitly a relation between the rock velocity and the effective pressure.

For geo-pressure estimation using velocities, we need a relationship between velocity and effective stress for a given lithology. By using Issler's relation, one obtains the following relationship that relates transit time to effective stress directly:

$$
\sigma=\frac{1}{k} \ln \left[\frac{\varphi_{o} d \tau^{\alpha}}{d \tau^{\alpha}-1}\right]
$$

where: $d \tau=d t / d t_{m}$, and $\alpha=1 / x$.

There are several empirical approaches to pressure prediction using velocity [6]-[10]. A popular empirical approach is Eaton's method [10] [11], which relates pore pressure to interval transit time. The pertinent equation for seismic or sonic logs is

$$
P=S-\left(S-P_{h}\right) *\left(d t / d t_{n}\right)^{3.0}
$$

where: $d t_{n}$ is the slowness for normally compacted rock.

Pressure prediction from seismic data has two major components: a rock model that relates effective stress to velocity, and the velocity field. The errors in the predicted pressure arise from both sources. It is true that even if the rock model were perfect an unlikely case there would still be errors in the predicted pore pressure due to inherent errors in the seismic velocity field.

\subsection{Pore Pressure Prediction from Drilling Parameters}

Mud loggers data are divided into two categories; real time data and lagged data. The LWD/MWD tool is a group of sensors equivalent to the wireline sensors built into the drill-string placed just behind the drill-bit. The signals are transmitted to surface by pressure pulsation in the mud, as well as being recorded in a memory built into the tool. As the sensors can be several meters behind the drill-bit the data are regarded as lagged data, i.e. the recording of the data does not correspond in time with the position of the bit, and hence the drilling response.

D-Exponent Methodology is considered to be an appropriate method of pore pressure estimation while drilling. The methodology for pore pressure prediction known as the D exponent is a function of an exponent of adjustment that was originally defined for the Gulf of Mexico [12]. A restriction of this methodology is the Normal Compact Trend (NCT), it needs to be interpreted from the data [13].

Accurate determination of pore pressure is of fundamental importance to prevent circulation losses or blowouts during drilling [13] [14]. Because no direct method exists to measure pore pressure in shales, planning and execution of new boreholes relies upon indirect methods [15]. Several methods such as Bowers [16], and D exponent [12] are available to estimate pore pressure in shales from indirect measurements.

Methods to detect and estimate abnormal formation pressure are based on the principle that abnormally pressured formations tend to be less compacted and more porous than formations of similar lithology at the same depth. As a result, drastic increases in formation porosity may indicate zones of abnormal pressure.

The D-exponent is a way of normalizing the rate of penetration (ROP) to extract the formation drillability or hardness. Bingham (1964) suggested the following relationship between ROP, weight on bit (WOB), bit rotating speed (RPM) and bit diameter (D) [17]. This methodology was developed with the goal of normalizing the penetration rate from drilling parameters. The method was proposed by based on the Bingham equation [18], which was developed to consider the differential pressure effect in normalizing penetration rate. Rehm and Mcledon (1971) modified Jorden \& Shirley's equation to include mud weight, as shown in the follows Equation [19]: 


$$
D=\frac{\log \left(\frac{R}{60 N}\right)}{\log \left(\frac{12 W}{10^{6} D}\right)} *\left(\frac{\rho_{\text {normal }}}{\rho_{\text {actual }}}\right)
$$

where:

$R=$ Penetration Rate $(\mathrm{ft} / \mathrm{h})$,

$N=$ RPM (Revolutions per minute),

$D=$ Bit Diameter, (in),

$W=$ Weight on the bit (lb),

$\rho_{\text {normal }}$ Normal Hydrostatic Gradient (ppg),

$\rho_{\text {actual }}$ Current mud Weight (ppg).

The procedure used for estimation of the pore pressure profile from the D-exponent is based on Eaton's correlation, [20], he used for the adjustment parameter $\mathrm{f}$ to determine from the D-Exponent. Eaton's Correlation is defined by:

$$
\frac{P}{\mathrm{Z}}=\frac{S}{\mathrm{Z}}-\left(\frac{S}{\mathrm{z}}-\frac{P_{n}}{\mathrm{Z}}\right) * f^{\alpha}
$$

where:

$P$ is pore pressure,

$Z$ is depth, $\mathrm{ft}$,

$P_{n}$ is normal pressure,

$\mathrm{p} / \mathrm{z}$ is the pore pressure gradient (psi/ft),

$s / z$ is the overburden pressure gradient (psi/ft), is the overburden pressure gradient (psi/ft),

$p_{n} / z$ is the normal pore pressure gradient (psi/ft),

$f^{\alpha}$ is the adjustment parameter.

The adjustment correlation parameter $f^{\alpha}$ depends on the data available, which may be sonic, resistivity, or conductivity logs, drilling parameters, etc. According to the above, the following equation is a function of drilling parameters only:

$$
\frac{p}{Z}=\frac{s}{Z}-\left(\frac{s}{Z}-\frac{p_{n}}{Z}\right) *\left[\frac{D}{D_{n}}\right]^{b}
$$

where:

$D$ is the D-exponent,

$D_{n}$ is the normal trend of the D-exponent (Normal Comp-action Trend, NCT).

Eaton (1972), using this methodology in the Gulf Coast proposed that the exponent $b$ varies between 1.2 and 1.5. This exponent depends on the regional geologic setting, since it involves the overburden and pressure gradient.

\subsection{Pore Pressure Prediction from Logs}

Hottmann (1965) and Zhang (2011) were probably the first ones to make the pore pressure prediction from shale properties derived from well log data (acoustic travel time/velocity and resistivity). Gardner (1974) proposed an equation that can be written in the following form to predict pore pressure:

$$
p_{f}=\sigma_{v}-\frac{\left(\alpha_{v}-\beta\right)\left(A_{1}-B_{1} \ln \Delta t\right)^{3}}{Z^{2}}
$$

where:

$P_{f}$ is the formation fluid pressure, psi,

$\alpha_{v}$ is normal overburden stress gradient (psi/ft),

$\beta$ is the normal fluid pressure gradient (psi/ft),

$A$ and $B$ are the constants, $A_{1}=82.776$ and $B_{1}=15.695$,

$\sigma_{v}$ is expressed in psi, 
$Z$ is depth (ft),

$\Delta t$ is the sonic transit time $\left(\mu_{s} / \mathrm{ft}\right)$.

\subsubsection{From Resistivity Logs}

The resistivity log was originally used for pressure detection; the log response is based on the electrical resistivity of the total sample, which includes the rock matrix and the fluid-filled porosity. Eaton $(1972,1975)$ presented the following equation to predict pore pressure gradient in shales using resistivity log:

$$
P_{p g}=O B G-\left(O B G-P_{n g}\right) *\left(\frac{R}{R_{n}}\right)^{n}
$$

where:

$P_{p g}$ is the formation pore pressure gradient.

$O B G$ is the overburden stress gradient.

$P_{n g}$ is the hydrostatic pore pressure gradient (normally $0.45 \mathrm{psi} / \mathrm{ft}$ or $1.03 \mathrm{MPa} / \mathrm{km}$, dependent on water salinity).

$R$ is the shale resistivity obtained from well logging.

$R_{n}$ is the shale resistivity at the normal (hydrostatic) pressure; $n$ is the exponent varied from 0.6 to 1.5 , and normally $n=1.2$.

Eaton's resistivity method is applicable in pore pressure prediction, particularly for young sedimentary basins, if the normal shale resistivity is properly determined. One approach is to assume that the normal shale resistivity is a constant.

\subsubsection{From Sonic Logs}

\section{1) Eaton's Method}

Eaton (1975) presented the following empirical equation for pore pressure gradient prediction from sonic compressional transit time:

$$
P_{p g}=O B G-\left(O B G-P_{n g}\right) *\left(\frac{\Delta t_{n}}{\Delta t}\right)^{3}
$$

where:

$t_{n}$ is the sonic transit time or slowness in shales at the normal pressure.

$O B G$ is the overburden stress gradient.

$\Delta t$ is the sonic transit time in shales obtained from well logging, and it can also be derived from seismic interval velocity.

This method is applicable in some petroleum basins, but it does not consider unloading effects. This limits its application in geologically complicated area, such as formations with uplifts. To apply this method, one needs to determine the normal transit time $\left(\Delta t_{n}\right)$.

\section{2) Bowers's Method}

Bowers (1995) calculated the effective stresses from measured pore pressure data of the shale and overburden stresses (using Equation (1)). The pore pressure can be obtained from the velocity as:

$$
p=\sigma_{v}-\left(\frac{V_{p}-V_{m l}}{A}\right)^{\frac{1}{B}}
$$

The effective stress and compressional velocity do not follow the loading curve if formation uplift or unloading occurs, and a higher than the velocity in the loading curve appears at the same effective stress. Bowers (1995) proposed the following empirical relation to account for the effect of unloading curves [16]:

$$
V_{p}=V_{m l}+A\left[\sigma_{\max \left(\sigma_{e} / \sigma_{\max }\right)}^{1 / U}\right]^{B}
$$

where:

$\sigma_{\max }$ is the estimate of the effective stress. Rearranging the previous equation the pore pressure can be ob- 
tained for the unloading case:

$$
p_{\text {ulo }}=\sigma_{v}-\left(\frac{V_{p}-V_{m l}}{A}\right)^{\frac{U}{B}} *\left(\sigma_{\max }\right)^{1-U}
$$

where:

$P_{u l o}$ is the pore pressure in the unloading case.

Bowers's method is applicable to many petroleum basins (e.g., the Gulf of Mexico). However, this method overestimated pore pressure when shallow formation is poorly- or un-consolidated, because the velocity in such a formation is very slow.

\section{3) Miller's Method}

The Miller sonic method describes a relationship between velocity and effective stress that can be used to relate sonic/seismic transit time to formation pore pressure. In Miller's sonic method an input parameter "maximum velocity depth", $d_{\max }$, controls whether unloading has occurred or not. If $d_{\max }$ is less than the depth (Z), unloading has not occurred; the pore pressure can be obtained from the following equation [21]:

$$
p=\left(V-1 /\left(\ln \left(\left(V_{m}-V_{m l}\right) /\left(V_{m}-V_{p}\right)\right)\right)\right)
$$

where:

$V_{m}$ is the sonic interval velocity in the matrix of the shale (asymptotic travel time at infinite effective stress, $V_{m}=14,000-16,000 \mathrm{ft} / \mathrm{s}$;

$V_{p}$ is the compressional velocity at a given depth;

$\lambda$ is the empirical parameter defining the rate of increase in velocity with effective stress (normally 0.00025 );

$d_{\max }$ is the depth at which the unloading has occurred. If $d_{\max } \geq Z$, then unloading behavior is assumed, the pore pressure in the unloading case is calculated from the following equation:

$$
p_{\text {ulo }}=\left(V-1 /\left(\ln \left[a_{m}\left(1-\left(V_{p}-V_{\text {ulo }}\right) /\left(V_{m}-V_{m l}\right)\right)\right]\right)\right)
$$

where:

$a_{m}$ is the ratio of slopes of the virgin (loading) and unloading velocities in the effective stress curves $\sigma_{\text {ulo }}$ (normally $a_{m}=1.8$ ) and $a_{m}=V_{p} / V_{\text {ulo }}$;

$\sigma_{u l o}$ is the effective stress from unloading of the sediment;

$V_{\text {ulo }}$ is the velocity where unloading begins.

In Eaton's original equation, it is difficult to determine the normal shale resistivity or the shale resistivity in the condition of hydrostatic pore pressure. One approach is to assume that the normal shale resistivity is a constant. However, the normal resistivity $\left(R_{n}\right)$ is not a constant in most cases, but a function of the burial depth. Thus normal compaction trendline needs to be determined for pore pressure prediction.

The following equation of the normal compaction trend of resistivity can be used:

$$
\ln R_{n}=\ln R_{o}+b Z
$$

where:

$R_{n}$ is the shale resistivity in the normal compaction condition;

$R_{o}$ is the shale resistively in the mudline;

$Z$ is the constant; and

$b$ is the depth below the mudline.

The Eaton's resistivity equation can be expressed in the following form:

$$
P_{p g}=O B G-\left(O B G-P_{n g}\right) *\left(\frac{R}{R_{o} \mathrm{e}^{b Z}}\right)^{3}
$$

where:

$R$ is the shale resistivity in the normal compaction condition;

$R_{o}$ is the shale resistively in the mudline;

$b$ is the slope of logarithmic resistivity normal compaction trendline. 


\section{Case Study in This Work}

Our case study will deal with an on shore well called "LAGIA-8” located in Sinai, (Gulf of Suez, Nukhul Formation at Gebel el Zeit), LAT.: 29 16'19.17"N and LONG.: 32 53'16.05"E. the LAGIA Field is located onshore in the North Western Sinai. It is estimated that the LAGIA Field might contain up to 89 MM Barrels of 16 - 19 degrees API oil in place.

\subsection{Geological Setting and Stratigraphic Frameworks}

The studied well represented by three formations from top to bottom as follows:

\subsubsection{Rudies Formation ( $32 \mathrm{ft}-1133 \mathrm{ft}$ )}

Rudies Formation consisted of shale: light to dark greenish gray shale, medium to dark gray, greenish gray, occasionally light green, soft to moderately firm, sub blocky to sub flaky, silty in part, highly calcareous in upper parts, non to slightly calcareous in middle parts, marly and fossilerfrous in parts of shale, Limestone and Gypsum. Limestone is Light brown to brown, creamy white, light gray, off white, occasionally grayish white, moderately hard to hard, cryptocrystalline, argillaceous, occasionally dolomitic, silty, sandy in part, no visible porosity, no oil shows. Gypsum is Colorless, white, off white, moderately hard, fine crystalline-crystalline. The penetration rate was averaged $20 \mathrm{ft} / \mathrm{hr}$ in limestone and $120 \mathrm{ft} / \mathrm{hr}$ in shale.

\subsubsection{Nukhul Formation ( $1133 \mathrm{ft}-1354 \mathrm{ft}$ )}

Nukhul Formation consisted of Sandstone, Limestone and shale. Sand is Colorless, transported to translucent, occasionally white, fine to very fine grain, moderately sorted, sub rounded to sub angular. Sandstone is tannish white, light brown, off white, fine to very fine grain, moderately sorted, sub rounded to rounded, moderately consolidated semi-friable, calcareous cement, siliceous cement in part, with traces of tannish white patchy oil staining, very pale yellow fluorescence moderately pale yellow streaming cut, slow cloudy pale yellow crush cut, no residual rig. Oil shows interval at (1212 ft - $1218 \mathrm{ft})$. Limestone is off white, creamy white, occasionally grayish white, moderately hard to hard, cryptocrstaline, occasionally dolomitic, silty, sandly in part, no visible porosity and no oil show. Shale is medium to light gray, greenish gray, grayish white, soft to moderately firm, sub blocky, silty in part, marly and calcareous. The penetration rate was averaged $25 \mathrm{ft} / \mathrm{hr}$ in Limestone, $35 \mathrm{ft} / \mathrm{hr}$ in Shale and $100 \mathrm{ft} / \mathrm{hr}$ in Sandstone.

\subsubsection{Eocene Formation (1354 ft - $1460 \mathrm{ft}$ )}

Eocene Formation consisted of Limestone, Limestone is white, off white, light brown, yellowish white, occasionally creamy white, moderately hard to hard, soft to moderately hard in parts, occasionally hard, cryptocrystalline, sandy in part, cherty in part, no visible porosity, no oil shows. The penetration rate was averaged $30 \mathrm{ft} / \mathrm{hr}$ Limestone.

\subsection{Methods of Pore Pressure Prediction}

The author will apply three different ways of pore pressure prediction to our well. At first we will apply the D-exponent method. Then, we will predict the pore pressure from the sonic log and finally we will use the resistivity log and we will correlate the three methods to see how accurate each method is:

\subsubsection{D-Exponent Method}

The drilling data for LAGIA-8 was provided for every $1 \mathrm{ft}$ these data included (ROP, WOB, RPM \& Mud Weight). We used the previously discussed d-exponent equation. Rehm and Mcledon (1971) modified Jorden\& Shirley's equation to include mud weight ( Equation Number (8)) to calculate the d-exponent for our well, and after applied and calculating the D-exponent for LAGIA-8 well, and plotted it versus depth to show the following graph in Figure 1(a). In addition to calculate of the pore pressure gradient $(p / z)$ for the pore pressure from the D-exponent. Therefore used of the Eaton's correlation at Equation (10).

The $\mathrm{D}$ exponent is known from our previous calculations. The $p n$ is also known; we assumed it to be 0.444 $\mathrm{lb} / \mathrm{gal}$ which is an average between the fresh water density $(0.433 \mathrm{lb} / \mathrm{gal})$ and the salt water density $(0.461 \mathrm{lb} / \mathrm{gal})$. What remain to calculate are the $s / z$ and the $D_{n}$. We calculated the overburden gradient using the density and NPHI log by plugging the density and porosity at a given depth in the equation: 


$$
s / z=\frac{\left[\rho_{m}(1-\phi)+\rho_{w}(\phi)\right]}{0.052}
$$

where:

$s / z$ is the overburden pressure gradient;

$R$ is the Resistivity;

$R_{n}$ is the normal Resistivity;

$n$ Exponent $(0.6$ - 1.5).

The $D_{n}$ is the normal d-exponent or the normal compaction trend of D-exponent. To calculate it we plotted a best fit straight line to generate a linear equation that gives the $D_{n}$. We made the best fit in the early (shallow) depth of d-exponent to assure it represents the normal pressure and show as following graph in Figure 1(b).

Since we have all our needed parameters we calculated the actual pore pressure gradient and we plotted it versus depth to give us the following graph in Figure 2.

Since we are sure of our drilling parameters data and the data was taken in real time so the given pore pressure is of a high certainty and will be used as a reference for the other methods.

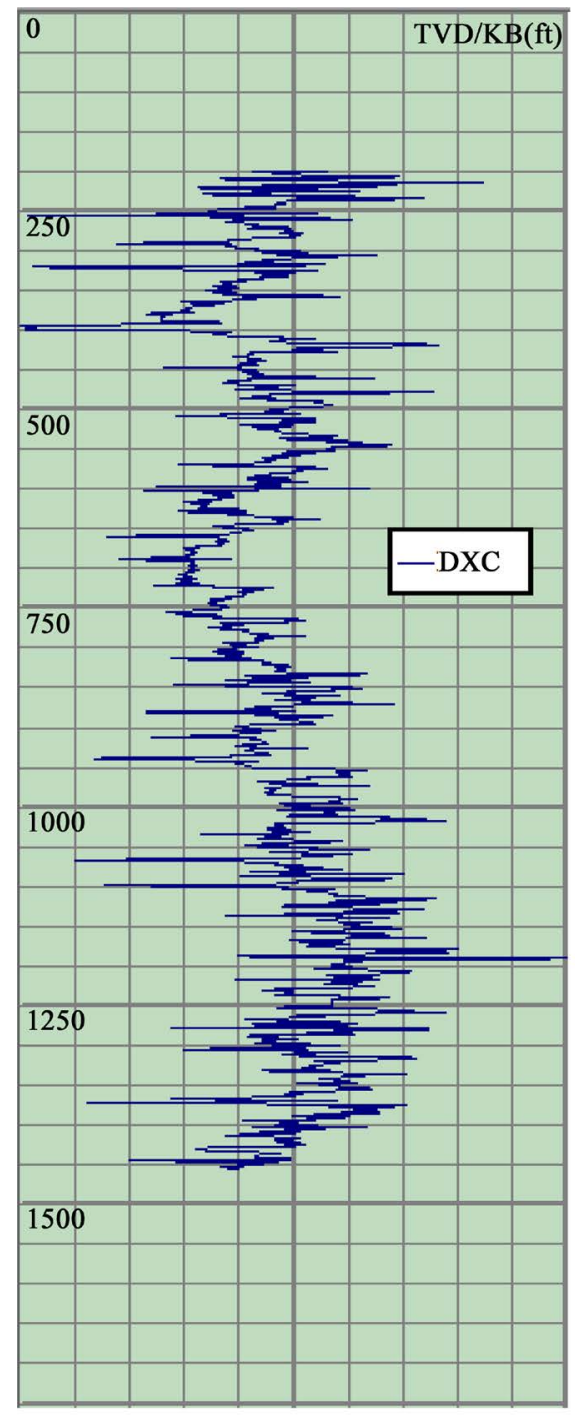

(a)

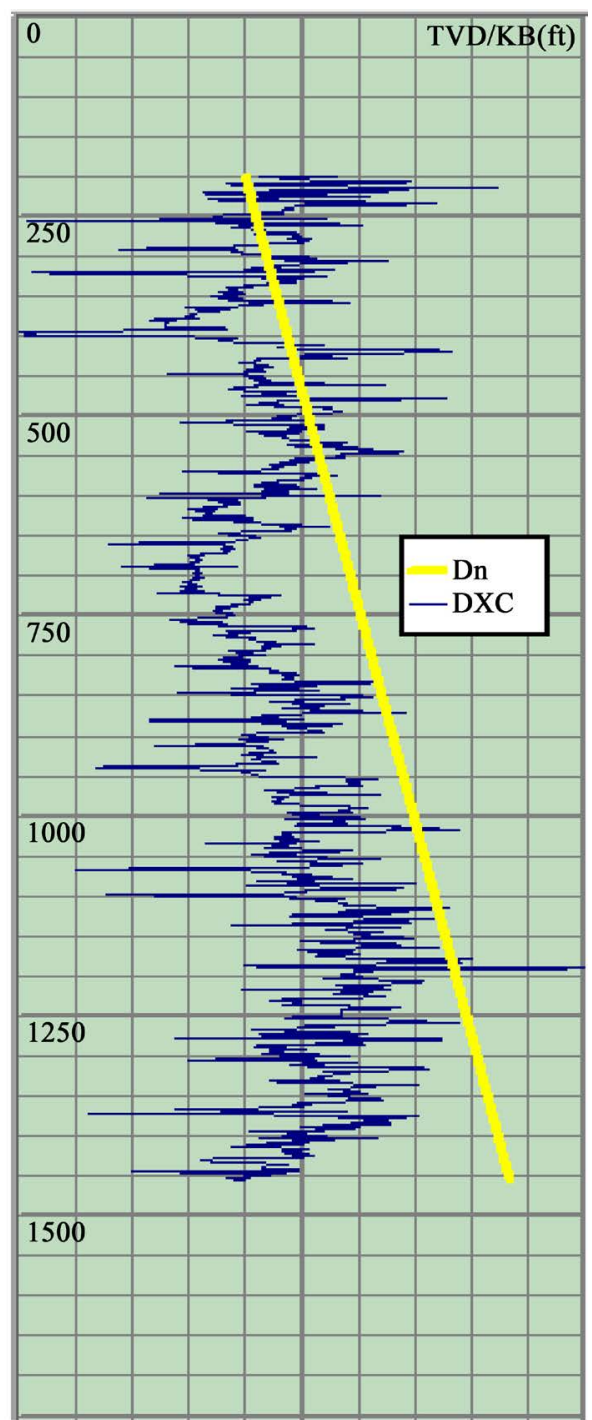

(b)

Figure 1. (a) Shows D-exponent versus depth for LAGIA-8 well; (b) The blue curve represents the d-exponent vs depth, while the yellow straight line represents the normal d-exponent. 


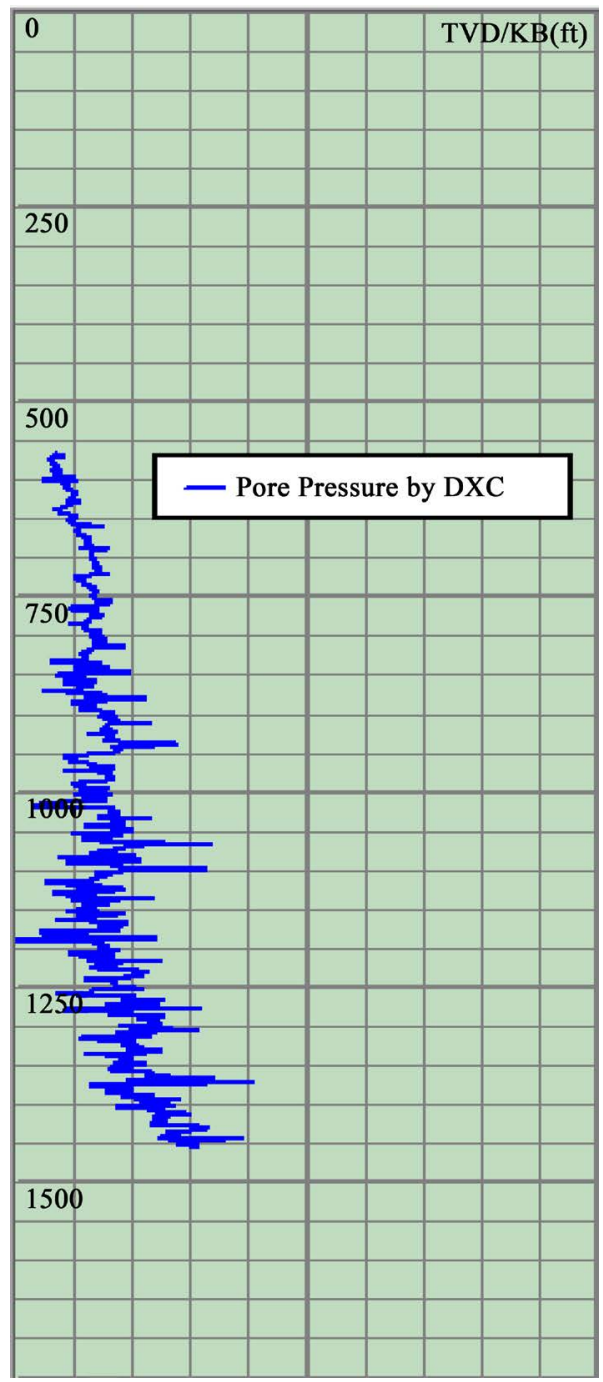

Figure 2. Pore pressure from D-exponent of case-1.

\subsubsection{Resistivity Log Method}

Theory: A deep resistivity log was run for LAGIA-8 and the recorded data was plotted on a semi log as follows the graph in Figure 3(a). After plotting the data, our next step was to predict the pore pressure from the resistivity log so we used the equation the Eaton's resistivity equation can be expressed in the following form:

$$
P_{p g}=O B G-\left(O B G-P_{n g}\right) *\left(\frac{R}{R_{n}}\right)^{n}
$$

where:

$P_{p g}$ is the actual pore pressure gradient;

$P_{n g}$ is the normal pore pressure gradient;

$O B G$ is the overburden pressure gradient;

$R$ is the Resistivity;

$R_{n}$ is the normal Resistivity;

$n$ Exponent (0.6 - 1.5).

The $O B G$ was calculated already in the first method of the d-exponent, as well as the $P_{n g}$. What is left to be calculated is the normal resistivity $R_{n}$. So, we used a straight line on the semi log graph to best-fit the resistivity graph and generate an equation for the $R_{n}$. The best fit line was as follows with graph in the Figure 3(b). 


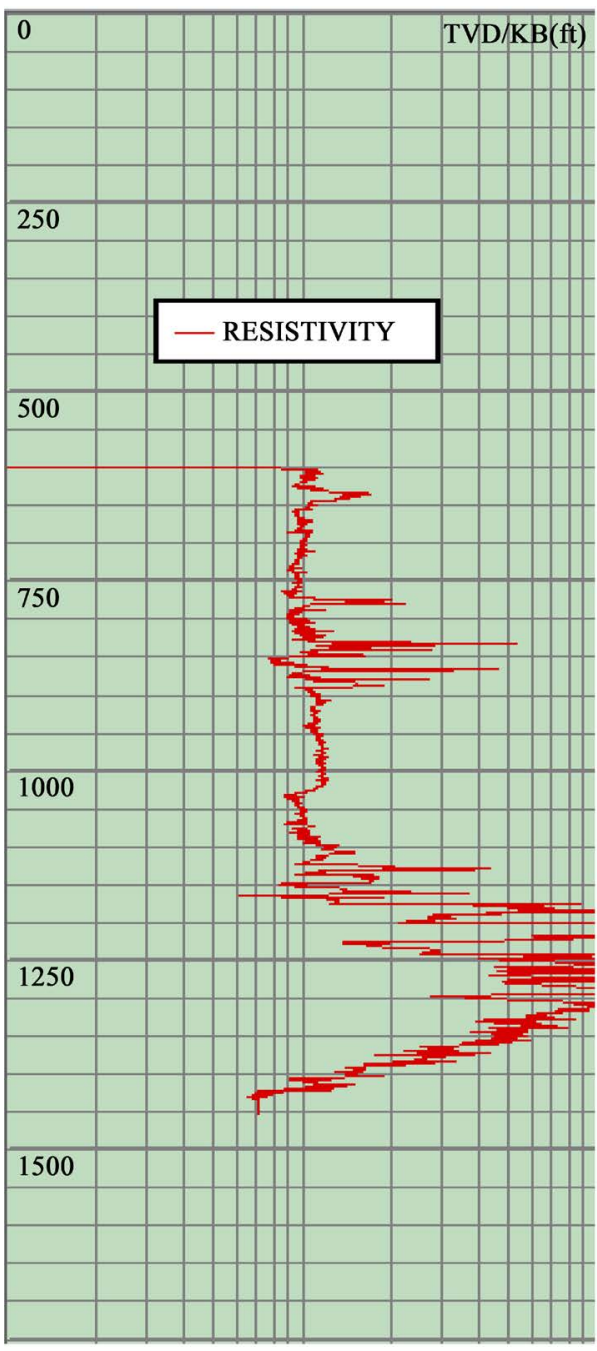

(a)

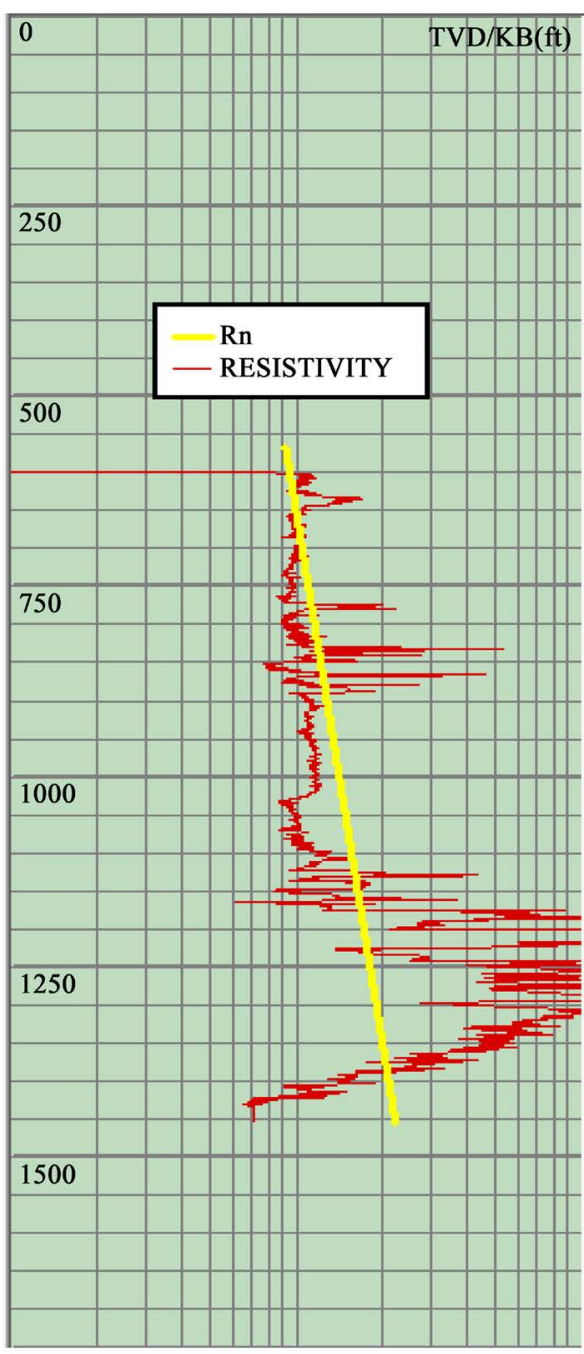

(b)

Figure 3. (a) Resistivity of case 1; (b) Normal resistivity of case 1, which the red curve, represents the resistivity versus depth, while the yellow straight line represents the normal resistivity and it best fits the shallow depth to represent the normal pore pressure.

Since we have all our needed parameters and we assumed the $\mathrm{n}$ to be 0.6 as by iteration it gave the most matching curve. So, we calculated the actual pore pressure gradient and we plotted it versus depth to give us the following the graph in Figure 4.

\subsubsection{Sonic Log Method}

Theory: A sonic log was run for LAGIA-8 and the recorded data was plotted on a semi log as follows the graph in the Figure 5(a). After plotting the data, our next step was to predict the pore pressure from the sonic log, so we used the empirical equation (Eaton's Method) for pore pressure gradient prediction from sonic compressional transit time [11], show the Equation Number (13).

The OBG was calculated already in the first method of the d-exponent, as well as the $P_{n g}$. What is left to be calculated is the normal transient time $\Delta t_{n}$. So, we used a best-fit line on the $\Delta t$ versus depth graph and generate an equation for the $\Delta t_{n}$. The best fit line was as follows the graph in Figure 5(b).

Since I have all my needed parameters, I calculated the actual pore pressure gradient and plotted it versus depth to give us the following the graph in Figure 6.

By plotting the three methods on the same graph to compare the pore pressure from the resistivity and the one from sonic log with the pore pressure from the d-exponent, and show the following graphs in Figure 7. 


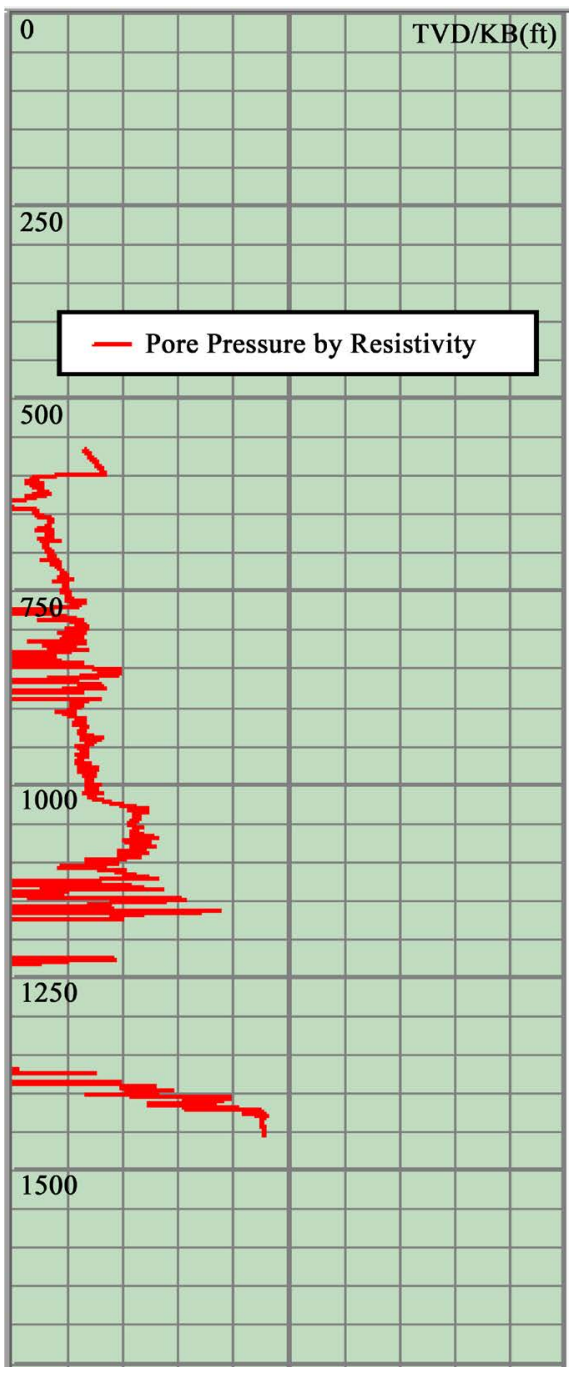

Figure 4. Pore pressure by resistivity versus depth.

As we see from this graph, there is a great match till the depth $900 \mathrm{ft}$ and after that the trends tend get a little bit away from each other however having the same trend. The deviation is seen clearly starting from depth 1150 which is almost the start of the Nukhul Formation which is mainly composed of sandstone. Since these methods depend on the calculation of the shale normal compaction trend so we expect to see this great deviation. These methods can be used in accurate pore pressure prediction in shale, but gives inaccurate readings when used in non-clastic rocks.

\section{Summary and Conclusions}

In this paper, the author applied three different ways of pore pressure prediction to our well. At first, I applied the D-exponent method, and then calculated the pore pressure from the sonic log and the resistivity logs. Finally, the previous methods were used to correlate pore pressure values with Seismic one.

\subsection{D-Exponent Method}

The drilling data for LAGIA-8 was provided for every $1 \mathrm{ft}$ these data included (ROP, WOB, RPM \& Mud Weight). I used the previously discussed d-exponent equation modified Jorden \& Shirley's equation to include mud weight ( Equation Number (8)) to calculate the d-exponent for our well, and after applied and calculating the D-exponent for LAGIA-8 well, and plotted it versus depth. Since we are sure of our drilling parameters data 
and the data was taken in real time so the given pore pressure is of a high certainty and will be used as a reference for the other methods.

\subsection{Resistivity Log Method}

Theory: A deep resistivity log was run for LAGIA-8 and the recorded data was plotted on a semi log. After plotting the data, our next step was to predict the pore pressure from the resistivity log so we used the equation the Eaton's resistivity equation.

Since I have all the needed parameters and by assumed the $\mathrm{n}$ to be 0.6 as by iteration it gave the most matching curve. So, I calculated the actual pore pressure gradient and we plotted it versus.

\subsection{Sonic Log Method}

The pore pressure from the sonic log was calculated by using the empirical equation for pore pressure gradient prediction from sonic compression transit time.

It was clearly that, there is a great match till the depth $900 \mathrm{ft}$ and after that the trends tend get a little bit away from each other however having the same trend. The deviation is seen clearly starting from depth 1150 which is

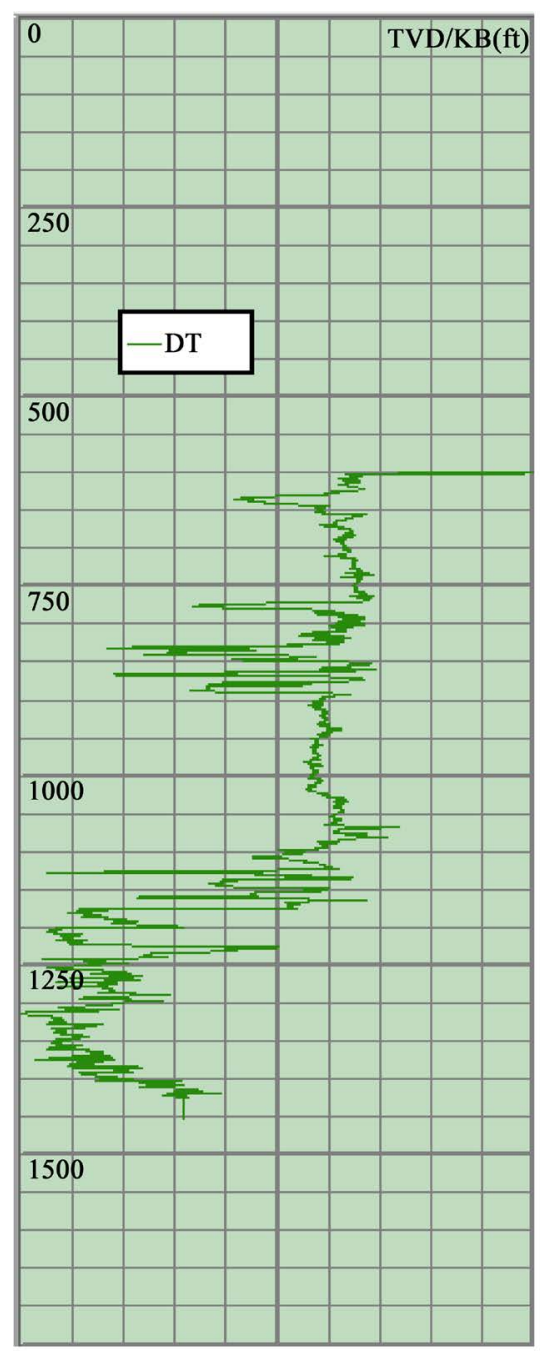

(a)

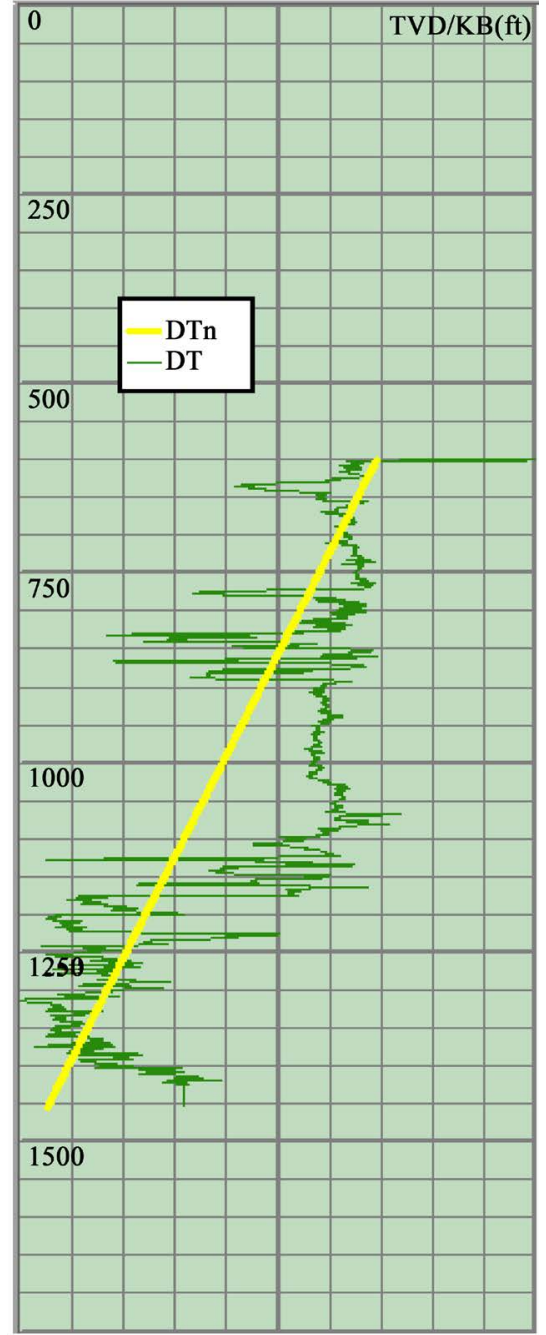

(b)

Figure 5. (a) Sonic Log Data of LAGIA -8 well; (b) The green curve represents the transient time versus depth, while the yellow straight line represents the normal transient time and it best fits the shallow depth to represent the normal pore pressure. 


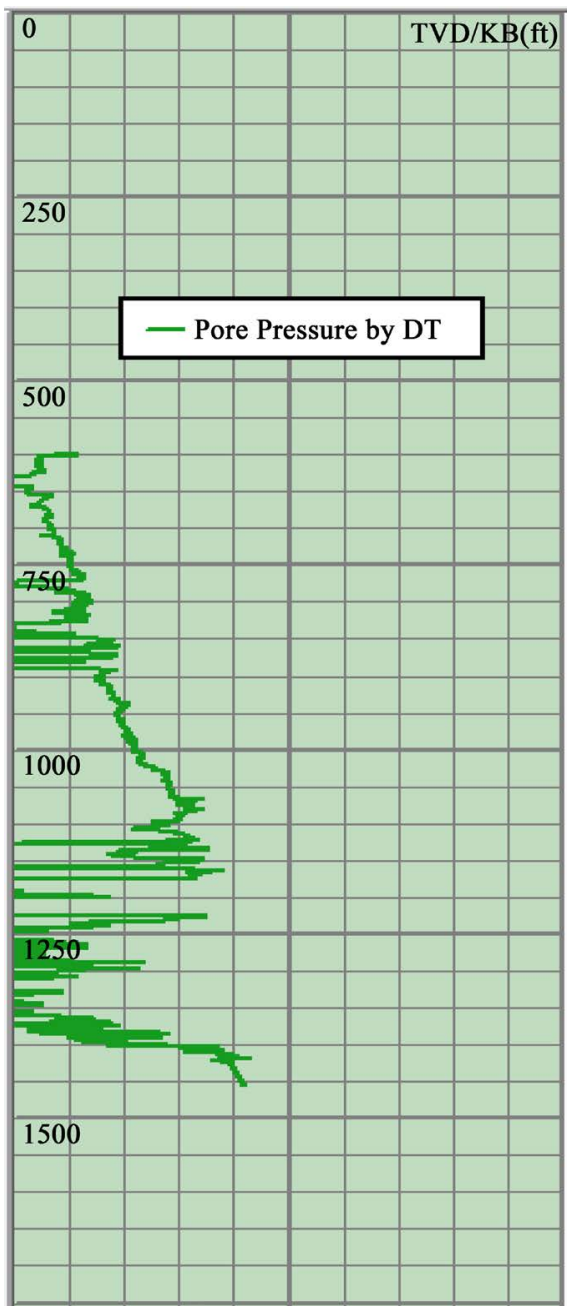

Figure 6. Pore pressure from transit time.

almost the start of the Nukhul Formation which is mainly composed of sandstone. Since these methods depend on the calculation of the shale normal compaction trend so I expect to see this great deviation. These methods can be used in accurate pore pressure prediction in shale, but gives inaccurate readings when used in non-clastic rocks. When I plotted the three methods on the same graph to compare the pore pressure from the resistivity and the one from sonic log with the pore pressure from the d-exponent, it was clearly that their values shows a coincidence in their values which reflect the accuracy in calculations using these three methods.

\subsection{Pore Pressure Prediction from Seismic}

Pressure prediction from seismic data is based on fundamentals of rock physics and seismic attribute analysis. This paper hence tries to assess the use of seismic waves as a viable means to calculate pore pressure, especially in areas where no prior drilling history can be found. Then I applied these methods on LAGIA-8 well, Sinai, Egypt as a case study.

Determining pore pressure from seismic interval velocities is not different with using the sonic log. The important difference is that the interval velocities that are calculated from the RMS velocities coming from stacking velocities are horizontal velocities while the sonic log is measuring the vertical velocity assuming the well is vertical.

Seismic velocities have long been used to estimate pore pressure, indeed both these quantities are influenced by variations in rock properties such as porosity, density, effective stress and so on, and high pore pressure zones are often associated with low seismic velocities. 


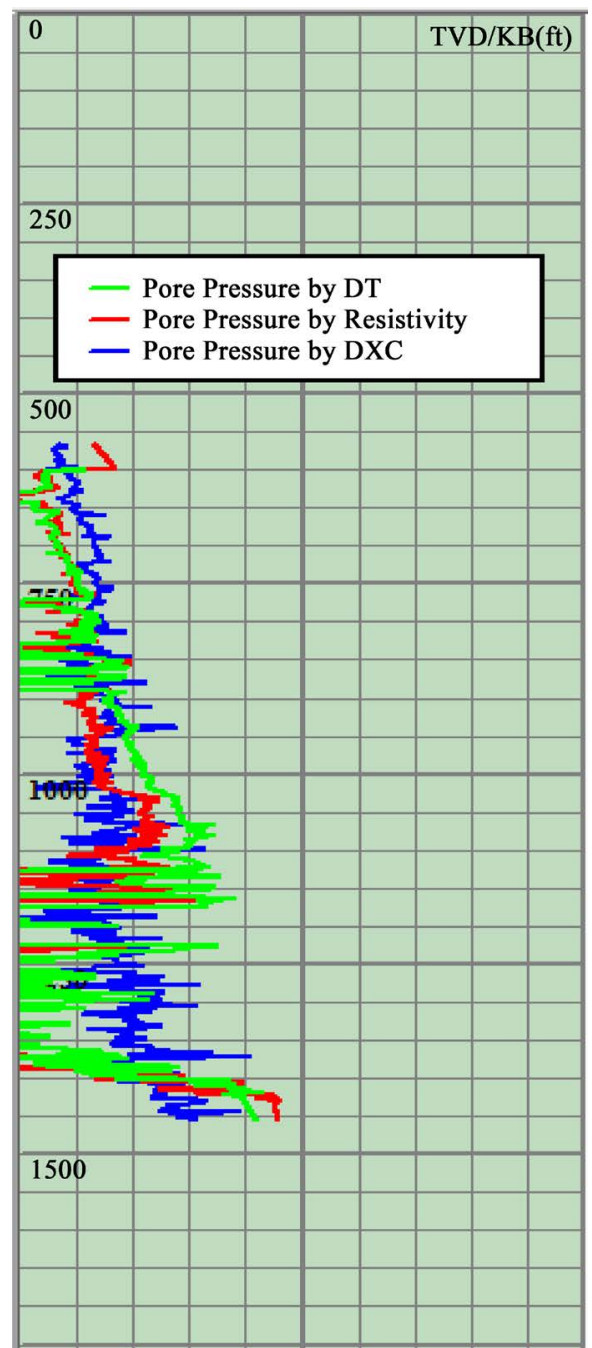

Figure 7. Comparison between pore pressure from three different methods such as D-exponent, resistivity and transit time.

From all the above we can conclude that, pore pressure prediction from Seismic is a very essential tool to predict pore pressure before drilling operation. This could prevent the well problem as well blowout and to prevent formation damage, especially in areas where no prior drilling history can be found.

\section{References}

[1] Nur, A.M. and Wang, Z., Eds. (1989) Seismic and Acoustic Velocities in Reservoir Rocks, 1: Experimental Studies. Society of Exploration Geophysicists.

[2] Pickett, G.R. (1963) Acoustic Character Logs and Their Application in Formation Evaluation. Journal of Petroleum Technology, 15, 659-667. http://dx.doi.org/10.2118/452-PA

[3] Gardner, G.H.F., Gardner, L.W. and Gregory, A.R. (1974) Formation Velocity and Density the Diagnostic Basis for Stratigraphic Traps. Geophysics, 39, 2085-2095. http://dx.doi.org/10.1190/1.1440465

[4] Wyllie, M.R.J. (1957) The Fundamentals of Log Interpretation. 2nd Edition, Academic Press.

[5] Issler, D.R. (1992) A New Approach to Shale Compaction and Stratigraphic Restoration; Beaufort-McKenzie Basin and McKenzie Corridor, North Canada. AAPG Bulletin, 8, 1170-1189.

[6] Raiga-Clemenceau, R.S. and Bacon, M. (1988) Sesmic Amplitude: An Interpreter’s Handbook. Cambridge University Press, Cambridge.

[7] Archie, G.E. (1942) The Electric Resistivity Log as an Aid in Determining Some Reservoir Characteristics. Transactions on AIME, 164, 54-62. http://dx.doi.org/10.2118/942054-G 
[8] Hottmann, C.E. and Johnson, R.K. (1965) Estimation of Formation Pressures from Log-Derived Shale Properties. Journal of Petroleum Technology, 17, 717-722. http://dx.doi.org/10.2118/1110-pa

[9] Matthews, W.R. and Kelly, J. (1967) How to Predict Formation Pressure and Fracture Gradient. Oil and Gas Journal, 65, 92-1066.

[10] Eaton, B.A. (1968) Fracture Gradient Prediction and Its Application in Oil Field Operations. Journal of Petroleum Technology, 25-32.

[11] Eaton, B.A. (1972) The Effect of Overburden Stress on Geo-Pressures Prediction from Well Logs. Journal of Petroleum Technology.

[12] Jorden, J.R. and Shirley, O.J. (1966) Application of Drilling Performance Data to Overpressure Detection. Journal of Petroleum Technology, 1387-1394. http://dx.doi.org/10.2118/1407-PA

[13] Mouchet, J.P. and Mitchell, A. (1989) Abnormal Pressure While Drilling. Manuals Techniques 2. Boussens, France. Elf Aquitaine Editions.

[14] Bourgoyne, A.T., Chenevert, M.E., Milheim, K.K. and Young Jr. (1991) Applied Drilling Engineering. SPE Textbook, Series 2.

[15] Yoshida, C., Ikeda and Eaton, B.A. (1996) An Investigative Study of Recent Technologies Used for Prediction, Detection, and Evaluation of Abnormal Formation Pressure and Fracture Pressure in North and South America. IADC/SPE 36381, Kuala Lumpur, 9-11 September.

[16] Bowers, G.L. (1995) Pore Pressure Estimation from Velocity Data; Accounting for Overpressure Mechanisms besides under Compaction. SPE Drilling and Completions, 89-95.

[17] Bingham, M.G. (1964) A New Approach to Interpreting Rock Drillability. The Petroleum Publishing Co.

[18] Bingham (1969) A New Approach to Interpreting Rock Drillability. The Petroleum Publishing Co.

[19] Rehm and Mcledon (1971) Measurement of Formation Pressure from Drilling Data. SPE 3601, 1971, SPE Reprint Series No. 6a, 1971 Revision.

[20] Eaton, B.A. (1975) The Equation for Geopressure Prediction from Well Logs. Society of Petroleum Engineers of AIME, Paper SPE 5544.

[21] Zhang, J. (2011) Pore Pressure Prediction from Well Logs: Methods, Modifications. Elsevier, 50-63. 